\title{
PENGARUH MUTU PELAYANAN PERPAJAKAN DAN KEPUASAN WAJIB PAJAK TERHADAP KEPATUHAN WAJIB PAJAKPADA SISTEM E-FILING PERPAJAKAN DI INDONESIA
}

\author{
Yohanes Mardinata Rusli \\ Fakultas Ilmu Sosial dan Humaniora Universitas Bunda Mulia \\ yrusli@bundamulia.ac.id
}

\begin{abstract}
ABSTRAK
Penelitian ini bertujuan ingin mengetahui pengaruh antara mutu pelayanan perpajakan dan kepuasaan wajib pajak terhadap kepatuhan wajib pajak orang pribadi di lingkungan yayasan pendidikan bunda mulia. Penelitian ini menggunakan metode penelitian analitis kuantitatif, dimana data diperoleh melalui penyebaran kuisioner kepada wajib pajak orang pribadi pada lingkungan yayasan pendidikan Bunda Mulia di Jakarta. Data yang diperoleh kemudian diolah dengan menggunakan software SPSS 23. Hasil penelitian ini menunjukkan adanya: (a) hubungan positif dan signifikan antara mutu pelayanan perpajakan petugas pajak (fiskus) terhadap kepatuhan wajib pajak orang pribadi; (b) hubungan positif dan signifikan antara kepuasan wajib pajak orang pribadi terhadap kepatuhan wajib pajak orang pribadi.Hasil penelitian menunjukkan bahwa mutu pelayanan perpajakan yang diberikan oleh petugas pajak (fiskus) berpengaruh positif terhadap kepatuhan wajib pajak orang pribadi pada sistem e-filing perpajakan di Indonesia. Selain itu, tingkat kepuasan wajib pajak orang pribadi di lingkungan yayasan pendidikan bunda mulia juga berpengaruh positif dan signifikan terhadap kepatuhan wajib pajak orang pribadi pada sistem e-filing perpajakan di Indonesia. Penelitian ini memiliki kontribusi di dalam membantu dan mendukung program penyelenggaraan sistem $e$-filing yang diselenggarakan oleh Kementerian Keuangan Republik Indonesia, khusunya Direktorat Jenderal Pajak (DJP).
\end{abstract}

Kata Kunci: mutu pelayanan perpajakan, kepuasan wajib pajak, kepatuhan wajib pajak, wajib pajak orang pribadi, sistem e-filing perpajakan. 


\title{
National Conference of Creative Industry: \\ Sustainable Tourism Industry for Economic Development
}

Universitas Bunda Mulia, Jakarta, 5-6 September 2018

e-ISSN No: 2622 - 7436

\begin{abstract}
This study is intended to determine the effect of the tax service quality and satisfaction of taxpayers on tax compliance within the individual educational foundation noble mother. This study uses quantitative analytical research method, where the data obtained through the distribution of questionnaires to individual taxpayers in the environment of Bunda Mulia education foundation in Jakarta. Data obtained then processed by using software SPSS 23. The results of this study indicate the existence of: (a) positive and significant relationship between the qualities of tax service tax officer (tax) to the taxpayer compliance of individuals; (b) a positive and significant relationship between the satisfactions of individual taxpayers on individual taxpayer compliance.The results represent that the quality of tax services provided by tax officials (tax authorities) have a positive effect on taxpayer compliance of individuals on the system of e-filing taxation in Indonesia. In addition, the level of personal taxpayer satisfaction in the noble education foundation also has a positive and significant impact on the taxpayer compliance of individuals on the tax e-filing system in Indonesia. This research has contributed in assisting and supporting the implementation of e-filing system organized by the Ministry of Finance of the Republic of Indonesia, especially the Directorate General of Taxation.
\end{abstract}

Keywords: quality of tax service, taxpayers satisfaction, taxpayer compliance, personal taxpayers,e-filing system of Indonesian taxation.. 


\section{National Conference of Creative Industry: \\ Sustainable Tourism Industry for Economic Development}

Universitas Bunda Mulia, Jakarta, 5-6 September 2018

e-ISSN No: 2622 - 7436

\section{PENDAHULUAN}

Pajak merupakan salah satu penerimaan negara yang sangat penting untuk pembiayaan dan stabilitasi pembangunan negara. Penerimaan negara dapat bersumber dari pajak, kekayaan alam, bea dan cukai, retribusi, iuran, sumbangan atau hibah, pinjaman, dividen dari BUMN dan Surat Utang Negara. Penerimaan negara ini akan mencakup kepentingan masyarakat bahkan individu (misalnya: Jamkesmas, biaya pendidikan gratis, beasiswa).

Masyarakat adalah kumpulan manusia yang pada suatu waktu berkumpul untuk tujuan tertentu, masyarakat terdiri dari individu, individu mempunyai hidup sendiri dan kepentingan sendiri. Namun, individu tidak mungkin hidup tanpa adanya masyarakat. Negara adalah masyarakat yang mempunyai tujuan tertentu.Kelangsungan hidup suatu negara juga berarti kelangsungan hidup masyarakat dan kepentingan masyarakat. Untuk kelangsungan hidup masing-masing diperlukan biaya, biaya hidup individu menjadi beban dari individu yang bersangkutan dan berasal dari penghasilannya sendiri. Biaya hidup negara adalah untuk kelangsungan alat-alat negara, administrasi negara, lembaga negara yang harus dibiayai dari penghasilan negara yang salah satunya berasal dari pemungutan pajak kepada masyarakat.

Perkembangan teknologi saat ini sangat pesat, beberapa perkembangan teknologi di dunia pada saat ini yang pesat yaitu perkembangan teknologi informasi dan teknologi internet. Kedua perkembangan teknologi tersebut yang sangat pesat dapat mengubah cara manusia di dalam bekerja, berusaha, bersosialisasi, berbagi informasi, mengatur orangorang dan ide-ide lainnya di segala penjuru dunia.

Perkembangan teknologi internet yang semakin hari mengalami kemajuan yang sangat pesat akan semakin mendorong terjadinya transformasi di dalam dunia bisnis. Selain itu perkembangan teknologi internet juga membuat modernisasi di dalam bidang perekonomian setiap negara di dunia. Hal tersebut membuat banyak pihak memperoleh keuntungan dari perkembangan teknologi internet tersebut, seperti: warga negara, konsumen, individu, sekelompok orang dan anggota satu komunitas.

Selain itu, pemerintah sebagai pembuat keputusan yang untuk perkembangan perekonomian suatu negara juga mendapatkan keuntungan dan dampak yang positif dari perkembangan teknologi internet tersebut pada sektor ekonomi dan dalam hal pelayanan kepada warga negara nya. Hal ini juga membuat Direktorat Jendera Pajak (DJP) sebagai lembaga yang mempunyai kewenangan mengenai hal perpajakan di Indonesia mengikuti perkembangan teknologi internet dan teknologi informasi tersebut dalam penerapan sistem pemungutan perpajakan yang berlaku di Indonesia saat ini, yaitu self-assessment system.

Self-assessment system merupakan system pemungutan pajak dimana Wajib Pajak diberikan kepercayaan untuk menghitung, mambayar, dan melaporakan kewajiban perpajakannya sendiri, bukan oleh pihak laian maupun pihak pemerintah / tax authorized. (UU KUP no.36 tahun 2009). Penerapan kemajuan teknologi internet dan teknologi informasi ini diterapkan dapam system administrasi perpajakan modern dengan pelayanan perpajakan yang berbasis pada e-system, seperti: e-registration, e-SPT, efaktur, e-filing, dan $e$-biling.

Penerapan untuk sistem modernisasi perpajakan di Indonesia yang mengikuti perkembangan teknologi internet dan teknologi informasi yang semakin maju saat ini, mendorong pemerintah yang dalam hal ini merupakan Direktorat Jenderal Pajak (DJP) sebagai lembaga yang mempunyai wewenang di dalam bidang perpajakan di Indonesia 


\section{National Conference of Creative Industry: \\ Sustainable Tourism Industry for Economic Development}

Universitas Bunda Mulia, Jakarta, 5-6 September 2018

e-ISSN No: 2622 - 7436

dibawah kementerian Keuangan Republik Indonesia harus bekerja lebih keras untuk meyakinkan masyarakat sebagai Wajib Pajak untuk mau melakukan kewajiban perpajakannya dengan menggunakan teknologi internet dan teknologi informasi yang sudah maju saat ini dengan berbasis pada $e$-system yang sudah diterpakan oleh Direktorat Jenderal Pajak (DJP) beberapa tahun belakangan ini.

Untuk dapat menjalankan kewajiban perpajakan yang baik dengan sistem saat ini yang diterapkan oleh Direktorat Jenderal Pajak (DJP), maka untuk dapat membuat para wajib pajak dalam hal ini taxpayers, maka pemerintah melakukan beberapa sistem modernisasi perpajakan yang mengikuti perkembangan teknologi internat dan sistem teknologi informasi. Agar sistem modernisasi perpajakan ini dapat berjalan dengan cepat dan baik, maka diperlukannya advokasi dari pihak Direktorat Jenderal Pajak (DJP) kepada pihak Wajib Pajak sebagai konsumen nya yang di dalam perpajakan di Indonesia bersifat memaksa dan tidak mendapatkan kontrapretai langsung.

Menurut Vathanopas et al. (2015), perkembangan teknologi yang pesat dari pengguna internet dan e-commerce mengakibatkan meningkatnya tingkat tekanan tehadap pemerintah untuk pengelolahan kebutuhan warga negara melalui media yang bernama electronic government, yang biasanya disebut e-Governance. E-Governance lebih kepada penggunaan teknologi informasi oleh pihak pemerintahan, seperti jaringan berbasis web, internet, dan computer mobile, yang mempunyai kemampuan untuk memberikan informasi dan mentransformasi hubungannya dengan warga negara (Fang, 2002).

Beberapa negara di dunia ini, baik negara maju, negara berkembang, dan negara tidak berkembang telah melakukan program e-government meskipun negara-negara tersebut memiliki tingkat indeks pengembangan yang berbeda-beda. Indonesia termasuk dalam kategori e-Governance Development Indeks (EGDI) menengah, yaitu yang memiliki nilai EGDI antara 0,25 - 0,50. Berdasarkan data peringkat e-Governance Development Indeks (EGDI), Indonesia menduduki peringkat e-Governance Development Indeks (EGDI) tahun 2016 pada urutan ke-116. Penetapan peringkat $e$-Governance Development Indeks (EGDI) dilakukan berdasarkan berdasarkan pengukuran penggunaan teknologi informasi dan teknologi komunikasi kepada layanan publik dengan mencakup 3 (tiga) dimensi, yaitu: (1) Scope dan kualitas layanan online; (2) status infrastruktur telekomunikasi; dan (3) kapasitas manusia yang ada.

Menurut beberapa peneliti, hambatan-hambatan yang dihadapi pemerintah dalam penerapan e-Government di Indonesia, antara lain: (1) adanya keterbatasan kompetensi sumber daya manusia dan infrastruktur serta belum tersedianya data lengkap mengenai penerapan e-Government di Indonesia (Amin, 2016); (2)terbatasnya regulasi sebagai paying hukum, belum adanya integrase data antar instansi pemerintah, format data yang berbeda, sistem keamanan informasi yang belum optimal, masih rawan di retas dan tidak dapat dijalankan secara maksimal karena terbatasnya tenaga-tenaga ahli yang mempunyai kompetensi dan integritas di bidang teknik informatika (Bayu. 2016).

Salah satu penerapan $e$-Government di Indonesia saat ini adalah sistem $e$-filing yang diterapkan oleh Direktorat Jenderal Pajak (DJP). Sistem e-filing ini merupakan sistem pelaporan pajak penghasilan yang melalui teknologi internet. E-filing merupakan suatu cara bagi wajib pajak di dalam menyampaikan pelaporan SPT secara elektronik yang dapat dilakukan dengan cara online dan real time melalui website yang dibuat oleh Direktorat Jenderal Pajak (DJP), yaitu www.pajak.go.id) dan juga aplikasi yang dibuat oleh penyedia jasa aplikasi (Application Service Provider). 


\section{National Conference of Creative Industry: \\ Sustainable Tourism Industry for Economic Development}

Universitas Bunda Mulia, Jakarta, 5-6 September 2018 e-ISSN No: 2622 - 7436

Penerapan sistem $e$-Filing dapat dinyatakan sebagai keberhasilan, jika tidak hanya tegantung dari dukungan dari pihak pemerintah, namun harus diikuti juga oleh minat warga negara untuk mengadopsi dan menerima pelayanan $e$-Governent, khususnya sistem e-Filing (Carter and Belanger, 2005). Pemerintah di Indonesia dalam hal ini yang operatinalisasinya dijalankan oleh Direktorat Jenderal Pajak-DJP dalam mengambil keputusan memerlukan pengertian mengenai faktor-faktor yang dapat mendorong dapat terciptanya peningkatan jumlah wajib pajak baru dan dapat menciptakan kepuasan bagi wajib pajak pengguna e-filing.

Hal ini dapat membuat wajib pajak yang puas dengan sistem e-filing ini akan mengubah prilakunya dalam melakukan pembayaran pajak yang akhirnya akan meningkatkan kepatuhan wajib pajak di dalam menjalankan kewajiban perpajakannya, yaitu: menghitung pajaknya, membayar pajaknya, dan melaporkan pajaknya. Sehingga dapat dikatakan bahwa jika pelayanan e-Governance di dalam sistem $e$-filing di dalam sistem perpajakan di Indonesia akan mempengaruhi tingkat kepuasan wajib pajak (tax $e$ satisfaction) di dalam menjalankan kewajiban perpajakannya.

Advokasi perpajakan bagi Wajib Pajak (WP) sangatlah penting di dalam mendukung sistem modernisasi perpajakan di Indonesia. Menurut Harrison (2001), advokasi adalah kemauan dari pelanggan untuk memberikan rekomendasi yang baik dan pujian kepada pelanggan lain atas nama produk atau layanan jasa penyediaanya. Pada penelitian ini pelanggan diartikan sebagai Wajib Pajak (Taxpayers), sedangkan perusahaan dalam hal penelitian ini diartikan sebagai Direktorat Jenderal Pajak (DJP) yang ada di dalam kementerian keuangan.

Wajib Pajak yang puas dengan sistem e-Governance yang mudah diterapkan oleh Direktorat Jenderal Pajak-DJP di dalam sistem e-Filing akan membuat wajib pajak melakukan advocacy taxation. Advocacy adalah seseorang yang merekomendasikan suatu produk atau merek dikarenakan mereka mencintai produk atau layanan dari lembaga tersebut (Kennedy, 2017). Menurut Thomas (2016), advocacy juga merupakan dimana seseorang merasa akan sangat positif terhadap sebuah layanan dan akan membagikan pengalaman positifnya tersebut kepada orang lain. Wajib pajak yang puas dengan pelayanan e-Government yang diterapkan oleh pemerintah (DJP) maka akan menimbulkan tingkat kepuasan wajib pajak sehingga wajib pajak tersebut akan mempengaruhi tax advocacy kepada wajib pajak lainnya, karena wajib pajak tersebut dengan kemauannya secara sukarela akan memberikan rekomendasi yang baik dan pujian kepada wajib pajak lain atas pelayanan perpajakan yang diterimanya.

Penelitian ini memiliki urgensi di dalam membantu dan mendukung program penyelenggaraan sistem e-Filing yang diselenggarakan oleh Kementerian Keuangan Republik Indonesia, khusunya Direktorat Jenderal Pajak (DJP). Sistem e-Filing yang dijalankan oleh Direktorat Jenderal Pajak (DJP) merupakan penerapan sistem $e$ Governmant yang mengikuti perkembangan teknologi internet dan teknologi informasi saat ini. Penerapan e-Governance yang baik oleh Direktorat Jenderal Pajak akan membuat wajib pajak puas terhadap pelayanan perpajakan yang dilakukan oleh DJP.Kepuasan Wajib Pajak di dalam mendapatkan pelayanan perpajakannya akan membuat Wajib Pajak tersebut memberikan rekomendasi terhadap kepuasan pelayanan yang diterimanya di dalam menjalankan kewajiban perpajakannya, sehingga diharapakan tingkat kepatuhan Wajib Pajak di Indonesia dalam menjalankan kewajiban perpajakannya akan terus meningkat. 


\section{National Conference of Creative Industry: \\ Sustainable Tourism Industry for Economic Development}

Universitas Bunda Mulia, Jakarta, 5-6 September 2018

e-ISSN No: 2622 - 7436

\section{TINJAUAN PUSTAKA}

\section{Theory of Planned Behavior (TPB)}

Theory of Planned Behavior (TPB)mendeskripsikan bahwa perilaku yang ditampilkan oleh individu timbul karena adanya niat untuk berperilaku. Sedangkan muncul niat berperilaku ditentukan oleh 3 faktor, yaitu: (1) behavioral beliefs, yaitu keyakinan individu akan hasil dari suatu perilaku dan evaluasi atas hasil tersebut (beliefs strength and outcome evaluation), (2) normatif beliefs, yaitu keyakinan tentang harapan normatif orang lain dan motivasi untuk memenuhi harapan tersebut (normatif beliefs and motivation to comply), dan (3) control beliefs, yaitu keyakinan tentang keberadaan halhal yang mendukung atau menghambat perilaku yang akan ditampilkan (control beliefs) dan persepsinya tentang seberapa kuat hal-hal yang mendukung dan menghambat perilaku tersebut (perceived power).

Hambatan yang mungkin timbul pada saat perilaku ditampilkan dapat berasal dari dalam diri sendiri maupun dari lingkungan. Secara berurutan, behavioral beliefs menghasilkan sikap terhadap perilaku positif atau negatif, normative beliefs menghasilkan tekanan sosial yang dipersepsikan (perceived social pressure) atau norma subyektif (subjective norm) dan control beliefs menimbulkan perceived behavioral control atau kontrol keperilakuan yang dipersepsikan (Ajzen, 2002:2)

\section{Gambar 1}

Theory of Planned Behavior

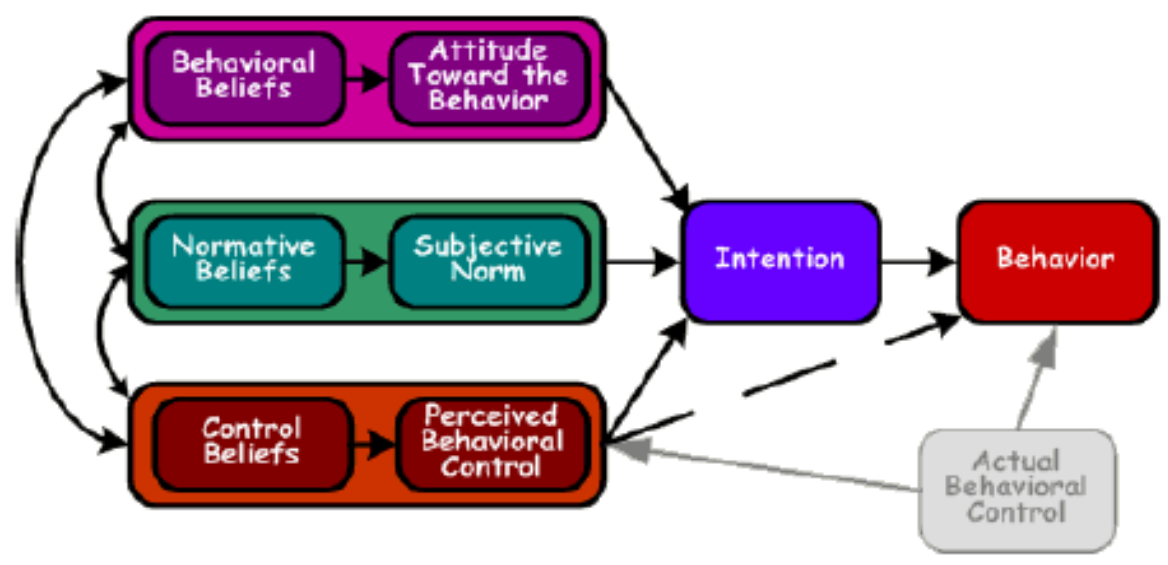

Sumber: Ajzen, I. (1991). The theory of planned behavior. Organizational Behavior and Human Decision Processes, 50, p. 179-211

\section{Knowledge Based Theory}

Knowledge didefinisikan sebagai kemampuan untuk bertindak yang dinamis, personal, dan berbeda dengan data dan informasi. Menurut Sveiby (1989), sifat dinamis dari pengetahuan yang dalam focus, gagasan kompetensi individu yang dapat digunakan sebagai sinonim yang adil. Sveiby (1989) membagi aktiva tidak berwujud menjadi tiga, yaiu: (1) Struktur eksternal dapat dilihat sebagai suatu aktiva tidak berwujud yang berhubungan dengan customer dan supplier, yang menjadi dasar bagi reputasi perusahaan; (2) Struktur internal dilihat dari tindakan yang dilakukan secara internal di dalam perusahaan. Struktur internal dapat dilihat pada bentuk paten, konsep, model, template, sistem komputer dan administrasi lainnya yang prosesnya lebih atau kurang eksplisit; (3) Kompetensi individual (the individual competence) terdiri dari 


\section{National Conference of Creative Industry: \\ Sustainable Tourism Industry for Economic Development}

Universitas Bunda Mulia, Jakarta, 5-6 September 2018 e-ISSN No: 2622 - 7436

kompetensi/staf teknis prefesional, ahli, riset dan penelitian, pekerja pabrik, penjualan dan pemasaran, dengan kata lain semua orang yang memiliki kontak langsung dengan pelanggan dan yang bekerja secara langsung mempengaruhi pandangan pelanggan terhadap organisasi.

\section{Mutu Pelayanan Perpajakan}

Pelayanan Berdasarkan Surat Edaran Direktur Jenderal Pajak No. SE-45/PJ/2007 yang telah dicabut dan mengalami perubahan SE- 84/PJ/2011 menyatakan bahwa, Pelayanan adalah tujuan utama dan indikator utama untuk membangun citra Direktorat Jenderal Pajak, sehingga peningkatan kualitas pelayanan dalam rangka membangun kepercayaan seluruh stakeholder dan mewujudkan harapan Wajib. Dapat disimpulkan pelayanan merupakan aktivitas - aktivitas yang dapat dirasakan dan tidak dapat terlihat akibat adanya interaksi antara pegawai pajak terhadap interaksi yang diberikan kepada Wajib Pajak sesuai dengan aturan pokok dan tata cara yang telah ditetapkan.

Mutu pelayanan merupakan totalitas pelayanan yang diberikan kepada konsumen agar harapan konsumen dapat terpenuhi secara maksimal. Keandalan adalah kemampuan memberikan layanan yang dijanjikan dengan segera, akurat, dan memuaskan. Menurut Tjiptono (2011) ada 5 dimensi kualitas pelayanan yaitu: (1) Daya tanggap adalah keinginan dan kesediaan para karyawan untuk membantu para pelanggan dan memberikan layanan dengan tanggap; (2)Jaminan yaitu mencangkup pengetahuan, kompetensi, kesopanan, dan sifat dapat dipercaya yang dimiliki ara karyawan, bebas dari bahaya fisik, risiko atau keragu-raguan; (3) Empati yaitu meliputi kemudahan dalam menjalin hubungan, komunikasi yang efektif, perhatian personal, dan pemahamanats kebutuhan individual para pelanggan; (4) Bukti fisik yaitu meliputi fasilitas fisik, perlengkapan, karyawan, dan sarana komunikasi; (5) Keandalan yaitu kemampuan untuk melaksanakan jasa yang dijanjikan dengan tepat dan terpercaya.

\section{Kepuasan Wajib Pajak}

Kepuasan pelanggan menurut Kotler (2005) adalah perasaan senang atau kecewa seseorang yang berasal dari perbandingan antara kesannya terhadap kinerja (atau hasil) suatu produk dan harapan-harapannya. Sementara itu, menurut Day dalam Tjiptono (2002) kepuasan atau ketidakpuasan pelanggan (wajib pajak) adalah respon pelanggan terhadap evaluasi ketidaksesuaian (disconfirmation) yang dirasakan antara harapan sebelumnya dan kinerja aktual produk/jasa yang dirasakan setelah pemakaiannya.

Dari beberapa definisi tersebut, dapat disimpulkan bahwa kepuasan merupakan fungsi dari persepsi atau kesan atas kinerja atau hasil yang dirasakan oleh pelanggan (wajib pajak). Jika kinerja pelayanan (pelayanan perpajakan) berada di bawah harapan pelanggan (wajib pajak), maka pelanggan (wajib pajak) akan tidak puas. Jika kinerja diatas harapan, maka pelanggan (wajib pajak) akan puas.

\section{Kepatuhan Wajib Pajak}

Kepatuhan perpajakan merupakan ketaatan pada undang-undang dan peraturan perpajakan yang berlaku serta tunduk dan patuh serta melaksanakan ketentuan perpajakannya. (Rahayu, 2010). Sedangkan menurut Jatmiko (2006), kepatuhan merupakan salah satu motivasi seseorang, kelompok atau organisasi untuk dapat berbuat atau tidak berbuat sesuai dengan aturan yang ditetapkan. 
Dalam pajak, aturan yang berlaku adalah Undang-undang Perpajakan. Kepatuhan pajak merupakan kepatuhan seseorang, dalam hal ini adalah wajib pajak, terhadap peraturan atau Undang-undang Perpajakan Kepatuhan perpajakan adalah tindakan wajib pajak dalam pemenuhan kewajiban perpajakannya sesuai dengan ketentuan peraturan perundang-undangan dan pertauran pelaksanaan perpajakan yang berlaku dalam suatu negara. Wajib pajak yang patuh adalah wajib pajak yang taat dan patuh serta tidak memiliki tunggakan atau keterlambatan penyetoran pajak.

Menurut Safri Nurmanto dalam Siti Kurnia Rahayu (2006) mengatakan bahwa kepatuhan perpajakan dapat didefinisikan sebagai suatu keadaan di mana Wajib Pajak memenuhi semua kewajiban perpajakan dan melaksanakan hak perpajakannya. Kepatuhan wajib pajak merupakan pemenuhan kewajiban perpajakan yang dilakukan oleh pembayar pajak dalam rangka memberikan kontribusi bagi pembangunan dewasa ini yang diharapkan di dalam pemenuhannya diberikan secara sukarela. Kepatuhan wajib pajak menjadi aspek penting mengingat sistem perpajakan Indonesia menganut sistem Self Asessment di mana dalam prosesnya secara mutlak memberikan kepercayaan kepada wajib pajak untuk menghitung, membayar dan melaporkan kewajiban perpajakannya.

Kepatuhan Wajib Pajak adalah keadaan dimana wajib pajak memenuhi semua kewajiban perpajakan dan melaksanakan hak perpajakan. Sikap Wajib Pajak yang memiliki rasa tanggungjawab sebagai warga negara bukan hanya sekedar takut akan sanksi dari hukum pajak yang berlaku, serta Wajib Pajak yang menyampaikan Surat Pemberitahuan dengan tepat waktu.

\section{Rerangka Konseptual}

\section{Gambar 2 - Rerangka Konseptual Penelitian}

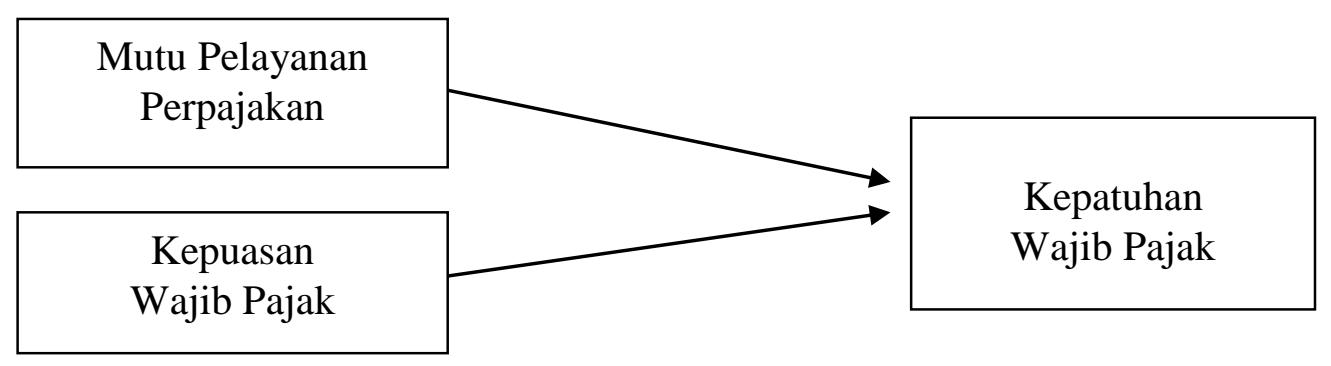

\section{Hipotesis Penelitian}

Berdasarkan paparan di atas, hipotesis yang akan diuji dalam penelitian ini adalah:

$\mathrm{H}_{1}$ : Mutu Pelayanan Perpajakan mempunyai pengaruh secara signifikan terhadap kepatuhan wajib pajak.

$\mathrm{H}_{2}$ : Kepuasan Wajib Pajak mempunyai pengaruh secara signifikan terhadap efektivitas pemrosesan data perpajakan wajib pajak. 


\section{National Conference of Creative Industry: \\ Sustainable Tourism Industry for Economic Development}

Universitas Bunda Mulia, Jakarta, 5-6 September 2018

e-ISSN No: 2622 - 7436

\section{METODE PENELITIAN}

Penelitian ini menggunakan metode kuantitatif dengan menggunakan jenis penelitian yang dilakukan dengan pendekatan dan data bersifat kuantitatif. Menurut Sujarweni (2014) penelitian kuantitatif adalah jenis penelitian yang menghasilkan penemuanpenemuan yang dapat dicapai dengan menggunakan prosedur-prosedur statistik. Sedangkan jenis penelitian yang digunakan dalam penelitian ini adalah penelitian kausal komparatif yang termasuk dalam bagian asosiatif atau hubungan.

Penelitian ini dilakukan dengan menyebarkan kuesioner kepada Wajib Pajak Orang Pribadi (WP OP) yang bekerja pada Yayasan Bunda Mulia di wilayah DKI Jakarta dan Serpongyang melakukan kewajiban perpajakannya di dalam melaporkan SPT Tahunan pajaknya. Penelitian ini menggunakan sampel yang terdiri dari 93 Wajib Pajak Orang Pribadi sebagai responden.

Menurut Sujarweni (2014) penelitian asosiatif bertujuan untuk mengetahui hubungan antar dua variabel atau lebih serta mengetahui pengaruhnya. Sementara menurut Hartono (2013) hipotesis asosiatif atau hubungan dapat diklasifikasikan kembali menjadi hipotesis korelasi dan hipotesis kausal. Hipotesis kausal adalah hipotesis yang menyebabkan perubahan variabel yang lainnya. Suryabrata (2014) menyatakan tujuan penelitian kausalkomparatif adalah untuk menyelidiki kemungkinan hubungan sebab-akibat dengan cara berdasar atas pengamatan terhadap akibat yang mencari kembali faktor yang mungkin menjadi penyebab melalui data tertentu.

Dalam penelitian ini yang menjadi subjek penelitian adalah para Wajib Pajak Orang Probadi (WPOP) yang bekerja pada Yayasan Bunda Mulia di wilyah Jakarta dan Serpong pada tahun 2017.

Objek penelitian dalam penelitian ini adalah efektivitas penerapan e-Government Tax Service Quality dan Tax e-Satification perpajakan Indonesia "self-assessment system" sebagai variabel independen, serta Taxpayers Advocacy sebagai variabel dependen.

Objek penelitian ini dipilih oleh peneliti dikarenakan sesuai Aanggaran Penerimaan dan Belanja Negara (APBN) yang menjadikan pajak sebagai tulang punggung penerimaan negara guna membiayai pembangunan negeri ini dan penerimaan dari sektor pajak diharapkan terus meningkat dari tahun ke tahun. Selain itu, sistem perpajakan Indonesia yang sudah berjalan sejak tahun 1983 (lebih dari tiga dekade) yaitu "self -assessment" dan sistem e-filing yang merupakan sebuah produk inovasi perkembangan teknologi informasi yang disediakan untuk memudahkan sekaligus meningkatkan pelayanan kepada para pembayar pajak dalam melaksanakan hak dan memenuhi kewajiban perpajakannya. 
Tabel 1

OPERASIONALISASI VARIABEL

\begin{tabular}{|c|c|c|}
\hline VARIABEL & INDIKATOR & $\begin{array}{c}\text { SKALA } \\
\text { PENGUKURAN }\end{array}$ \\
\hline $\begin{array}{l}\text { Mutu Pelayanan } \\
\text { Perpajakan(X1) } \\
\text { Papadomichelaki dan } \\
\text { Mentzas(2012); } \\
\text { Sharma (2015) }\end{array}$ & $\begin{array}{l}\text { 1. Keandalan sistem e-filling } \\
\text { perpajakan yang digunakan. } \\
\text { 2. Keamanan sistem e-filling } \\
\text { perpajakan yang digunakan. } \\
\text { 3. Efisiensi dengan adanya sistem } \\
\text { e-filing perpajakan } \\
\text { 4. Support Pemerintah (DJP) } \\
\text { pada sistem } e \text {-filing perpajakan }\end{array}$ & Interval \\
\hline $\begin{array}{l}\text { Kepuasan Wajib } \\
\text { Pajak (X2) } \\
\text { Shang(2014) }\end{array}$ & $\begin{array}{l}\text { 1. Kepuasan akan sistem e-filing } \\
\text { perpajakan yang ada } \\
\text { 2. Kepuasan akan pelayanan } \\
\text { fiskus kepada wajib pajak } \\
\text { 3. Kepuasan akan sistem } \\
\text { administrasi perpajakan } \\
\text { 4. Kepuasan akan sistem } \\
\text { informasi perpajakan } \\
\text { 5. Kepuasan terhadap fasilitas } \\
\text { perpajakan yang ada }\end{array}$ & Interval \\
\hline $\begin{array}{l}\text { Kepatuhan Wajib } \\
\text { Pajak (Y) } \\
\text { Yeh(2013) }\end{array}$ & $\begin{array}{l}\text { 1. Kemauan dari seorang wajib } \\
\text { pajak untuk memberikan } \\
\text { rekomendasi kepada wajib } \\
\text { pajak lainnya. } \\
\text { 2. Kepercayaan wajib pajak } \\
\text { terhadap sistem } e \text {-filing } \\
\text { perpajakan } \\
\text { 3. Loyalitas dari seorang wajib } \\
\text { pajak atas sistem } e \text {-filing } \\
\text { perpajakan }\end{array}$ & Interval \\
\hline
\end{tabular}

Sumber: Data diolah penulis (2018) 


\section{HASIL PENELITIAN DAN PEMBAHASAN}

Penyebaran serta pengembalian kuesioner dilaksanakan pada tanggal 09 Oktober 2017 sampai dengan 31 Oktober 2017. Dalam penyebaran kuesioner ini, sebanyak 130 kuesioner disebarkan, namun ada sebanyak 7 kuesioner yang tidak dikembalikan. Setelah semua kuesioner terkumpul, maka dilakukan proses pemilihan sampel dengan metode purposive sampling sehingga didapati bahwa ada sebanyak 18 kuesioner yang tidak dapat diolah dan sebanyak 105 kuesioner yang dapat diolah.

Tabel 2

STATISTIKA KUESIONER

\begin{tabular}{|l|l|l|}
\hline Keterangan & Jumlah & Persentase \\
\hline Kuesioner yang disebarkan & 130 & $100 \%$ \\
\hline Kuesioner yang tidak kembali & 7 & $5,38 \%$ \\
\hline Kuesioner yang tidak dapat diolah & 18 & $13,85 \%$ \\
\hline Kuesioner yang diolah & 105 & $80,77 \%$ \\
\hline
\end{tabular}

Sumber: data primer yang diolah peneliti (2018)

\section{Uji Persamaan Regresi Linier Berganda}

Analisis regresi linier berganda digunakan untuk mengetahui pengaruh antara variabel independen terhadap variabel dependen, yaitu antara variabel Mutu Pelayanan Perpajakan (X1), Kepuasan Wajib Pajak (X2) terhadap Kepatuhan Wajib Pajak (Y). Untuk mempermudah pembacaan hasil dan interpretasi regresi maka digunakan bentuk persamaan. Persamaan atau model tersebut berisi konstanta dan koefisien-koefisien regresi yang didapat dari hasil pengolahan data dengan program SPSS 23.0 yang disesuaikan dengan persamaan regresi. Adapun hasil uji regresi linier berganda adalah sebagai berikut:

Tabel 3

HASIL UJI REGRESI LINIER BERGANDA

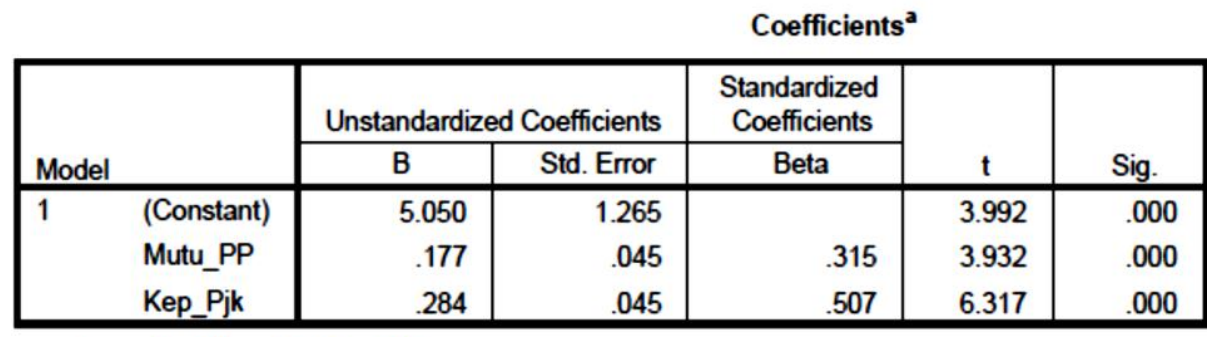

a. Dependent Variable: Kep_WP

Sumber: Data primer olahan SPSS(2018) 
Berdasarkan table 3 di atas hasil yang telah diperoleh dari koefisien regresi di atas, maka dapat dibuat suatu persamaan regresi sebagai berikut:

$$
\text { Kep_WP = 5,050 + 0,177 Mutu_PP + 0,284 Kep_Pjk + e }
$$

Dimana:

X1= Mutu Pelayanan Perpajakan (Mutu_PP)

X2= Kepuasan Wajib Pajak (Kep_Pjk)

$\mathrm{Y}=$ Kepatuhan Wajib Pajak (Kep_WP)

Pada persamaan regresi di atas nilai konstanta tercantum sebesar 5,050. Hal ini dapat diartikan jika variabel bebas dalam model persamaan yakni mutu pelayanan perpajakan di Indonesia dan Kepuasan Wajib Pajak di Indonesia diasumsikan konstan atau sama dengan bernilai nol (0), maka secara rata-rata variabel yang diukur model akan meningkatkan Kepatuhan Wajib Pajak sebesar 5,050 satuan. Konstanta sebesar 5,050 berarti bahwa seorang wajib pajak tetap melakukan kepatuhan wjaib pajak sebesar konstanta meskipun variabel lainnya berubah. Sehingga besarnya pengaruh tiap-tiap variabel independen terhadap variabel dependen adalah sebagai berikut:

a. Koefisien regresi variabel Mutu Pelayanan Perpajakan (X1) menunjukkan nilai sebesar 0,177 pada penelitian ini dapat diartikan bahwa variabel efektivitas penerapan sistem $e$-filing berpengaruh terhadap efektivitas pemrosesan data perpajakan. Hal ini menunjukkan bahwa ketika variabel $\mathrm{X}_{1}$ mengalami peningkatan sebesar satu satuan, variabel $\mathrm{Y}$ juga akan mengalami peningkatan sebesar 0,177 atau 17,70 \% dengan catatan variabel lain dianggap konstan.

b. Koefisien regresi variabel Kepuasan Wajib Pajak (X2) menunjukkan nilai sebesar 0,284 pada penelitian ini dapat diartikan bahwa variabel Kepuasan Wajib Pajak di Indonesiaberpengaruh terhadap Kepatuhan Wajib Pajak. Hal ini menunjukkan bahwa ketika variabel $\mathrm{X}_{2}$ mengalami penurunan sebesar satu satuan, variabel kualitas audit juga akan mengalami penurunan sebesar 0,284 atau 28,40\% dengan catatan variabel lain dianggap konstan.

\section{Analisis Koefisien Determinasi}

Koefisien determinasi bertujuan untuk mengukur seberapa jauh kemampuan model dapat menjelaskan variasi variabel dependen. Dalam pengujian hipotesis ini koefisien determinasi dilihat dari seberapa besar nilai Adjusted $R$ Square $\left(\mathrm{R}^{2}\right)$ untuk mengetahui seberapa jauh variabel bebas yaitu Efektivitas Penerapan Sistem E-Filingdan Modernisasi Sistem Perpajakan Indonesia terhadap Efektivitas Pemrosesan Data Perpajakan. Adapun hasil uji koefisien determinasi $\left(\mathrm{R}^{2}\right)$ adalah sebagai berikut:

\section{Tabel 4}

\section{HASIL UJI KOEFISIEN DETERMINASI}

\begin{tabular}{|l|c|r|c|r|}
\hline Model & $\mathrm{R}$ & R Square & $\begin{array}{c}\text { Adjusted R } \\
\text { Square }\end{array}$ & $\begin{array}{c}\text { Std. Error of } \\
\text { the Estimate }\end{array}$ \\
\hline 1 & $.723^{\mathrm{a}}$ & .523 & .514 & 1.47384 \\
\hline
\end{tabular}
a. Predictors: (Constant), Kep_Pjk, Mutu_PP
b. Dependent Variable: Kep_WP

Sumber: Data primer olahan SPSS (2018) 
Pada tabel 4diatas menyatakan bahwa nilai koefisien determinasi yang sudah disesuaikan (Adjusted $R$ Square) adalah 0,523. Hal ini berarti 52,30\% variasi dari penelitian kepatuhan wajib pajak di Indonesia dapat dijelaskan oleh variasi variabel independen yaitu mutu pelayanan perpajakan dan kepuasan wajib pajak yang terdapat dalam penelitian ini. Sedangkan sisanya sebesar 47,70\% dijelaskan atau dipengaruhi oleh variabel lain yang tidak ada dalam penelitan ini, namun faktor ini dapat mempengaruhi kepatuhan wajib pajak di Indonesia.

\section{Hasil Pengujian Hipotesis}

\section{Hasil Uji T}

Uji $\mathrm{T}$ digunakan untuk mengetahui pengaruh masing-masing variabel independen terhadap dependen yaitu antara efektivitas penerapan sistem e-filing dan modernisasi sistem perpajakan Indonesia terhadap efektivitas pemrosesan data perpajakan.

\section{Tabel 5}

\section{Hasil Uji T}

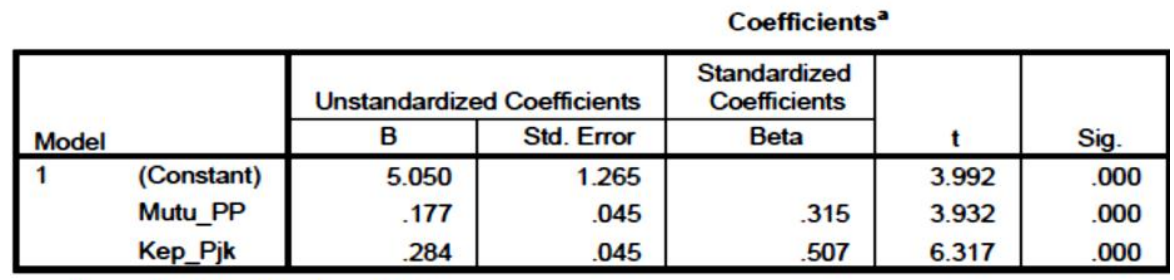

a. Dependent Variable: Kep_WP

Sumber: Data primer olahan SPSS (2018

\section{Uji Hipotesis 1: Pengaruh Mutu Pelayanan Perpajakan di Indoensia terhadap Kepatuhan Wajib Pajak}

Berdasarkan Tabel diatas diperoleh nilai t sebesar 3,932 dan nilai signifikansi sebesar 0,000 . Nilai t tabel yang diperoleh adalah sebesar 1,98793 dengan $\mathrm{df}=105$ dan tingkat sig. 0,05 . Jadi dapat disimpulkan bahwa nilai t hitung $>\mathrm{t}$ tabel $(5,494>1,987)$ dan nilai sig. $<0,05(0,000<0,05)$, sehingga $\mathrm{H}_{1}$ diterima, atau dengan kata lain variabel Mutu Pelayanan Perpajakan di Indonesia secara parsial berpengaruh signifikan terhadap variabel Kepatuhan Wajib Pajak di Indonesia.

\section{Uji Hipotesis 2 : Pengaruh Kepuasan Wajib Pajakterhadap Kepatuhan Wajib} Pajak

Berdasarkan table diatas, diperoleh nilai t sebesar 6,317 dan nilai signifikansi sebesar 0,001 . Adapun kriteria yang digunakan dalam penelitian ini adalah jika $t$ hitung $>t$ tabel atau nilai sig. $<0,05$, maka hipotesis diterima, dan jika $-\mathrm{t}$ tabel $\leq \mathrm{t}$ hitung $\leq \mathrm{t}$ tabel, maka hipotesis ditolak. Nilai t tabel yang diperoleh adalah sebesar 1,987 dengan $\mathrm{df}=105 \mathrm{dan}$ tingkat sig. 0,05. Jadi dapat disimpulkan bahwa nilai $t$ hitung $>\mathrm{t}$ tabel $(3,402>1,987)$ dan nilai sig. $<0,05(0,000<0,05)$, sehingga $\mathrm{H}_{2}$ diterima, atau dengan kata lain variabel Kepuasan Wajib Pajak secara parsial berpengaruh signifikan terhadap variabel Kepatuhan Wajib Pajak di Indonesia. 


\section{National Conference of Creative Industry: \\ Sustainable Tourism Industry for Economic Development}

Universitas Bunda Mulia, Jakarta, 5-6 September 2018 e-ISSN No: 2622 - 7436

Pengaruh Mutu Pelayanan Perpajakan (X1) terhadap Kepatuhan Wajib Pajak (Y)

Berdasarkan hasil analisis data penelitian yang telah diuraikan di atas, Setiap Wajib Pajak khususnya pada penelitian ini adalah Wajib Pajak Orang Pribadi (WPOP) yang bekerja pada Yayasan Bunda Mulia yang berdomisili di Jakarta dan Serpong di dalam menjalankan kewajiban perpajakannya yaitu melakukan kewajiban perpajakannya sehingga dapat merasakan secara langsung mutu pelayanan perpajakan yang diberikan oleh fiskus dalam hal ini DJP - Direktorat Jenderal Pajak di masing-masing KPP domisili wajib pajak tersebut yang dilakukan secara baik dan efektif maka akan berpengaruh positif secara signifikan terhadap kepatuhan wajib pajak dalam melaksanakan kewajiban perpajakannya.

Semakin baik mutu pelayanan perpajakan yang diberikan oleh fiskus dalam hal ini pihak DJP - Direktorat Jenderal Pajak di dalam pelayanannya, maka seorang Wajib Pajak dalam melakukan kewajiban perpajakannya di dalam melaporkan SPT Pajak Tahunannya secara sistem $e$-filing, maka akan berpengaruh terhadap kepatuhan wajib pajak di Indonesia. Hal ini sejalan dengan penelitian yang dilakukan oleh Sharma (2015) bahwa mutu pelayanan perpajakan yang baik akan membuat seorang wajib pajak khusunya WPOP (Wajib Pajak Orang Pribadi) akan meningkatkan kepatuahan Wajib Pajak dalam melakukan pelaporan perpajakannya dengan sistem e-filing perpajakan di Indonesia. Dengan demikian maka akan membuat efektivitas pelayanan perpajakan di Indonesia, dikarenakan penerapan sistem e-filing yang efektif yang dijalankan oleh pihak pemerintah dalam hal ini DJPDirektorat Jenderal Pajak Kementrian Keuangan RI, akan meningkatkan tingkat kepatuhan wajib pajak orang probadi di Indonesia.

\section{Pengaruh Kepuasan Wajib Pajak $\left(\mathbf{X}_{2}\right)$ terhadap Kepaatuhan Wajib Pajak pada sistem e-filling di Indonesia (Y)}

Berdasarkan hasil analisis data penelitian yang telah diuraikan di atas, kepuasan wajib pajak yang dirasakan oleh Wajib Pajak Orang Prinadi di Indonesia selama ini yang dilakukan oleh pihak fiskus (Direktorat Jenderal Pajak) sebagai lembaga tinggi negara yang berwenang di dalam menjalankan tanggung jawab di dalam mereformasi sistem perpajakan Indonesia.

Modernisasi administrasi perpajakan meliputi reformasi kebijakan, reformasi administrasi dan reformasi pengawasan. Reformasi kebijakan terdiri dari amandemen undang-undang antara lain UU No. 36 tahun 2008 mengenai Pajak Penghasilan, UU No. 16 tahun 2009 mengenai Ketentuan Umum dan Tata Cara Perpajakan (KUP), UU No. 42 tahun 2009 mengenai PPN dan PPnBM. Reformasi administrasi merupakan.

Kepuasan Wajib Pajak Orang Pribada yang semakin dirasakan baik maka akan mempengaruhi tingkat kepatuhan wajib pajak di dalam menjalankan kewajiban perpajakannya. Sehingga target penerimaan negara dari sektor pajak penghasilan dapat tercapai (Susanta et al., 2013). Selain itu, kepuasan wajib pajak yang dirasakan oleh wajib pajak orang pribadi mendorong pihak fiskus dalam hal ini Direktorat Jenderal Pajak (DJP) untuk semakin meningkatkan pelayanannya sehingga wajib pajak orang pribadi di dalam melaksanakan kewajiban perpajakannya akan semakin sadar (tax awareness), sehingga akan membuat wajib semakin patuh di dalam menjalankan kewajiban perpajakannya (Rusli, 2013). 


\section{National Conference of Creative Industry: \\ Sustainable Tourism Industry for Economic Development}

Universitas Bunda Mulia, Jakarta, 5-6 September 2018

e-ISSN No: 2622 - 7436

\section{KESIMPULAN DAN IMPLIKASI}

Berdasarkan hasil penelitian dan pembahasan yang telah dilakukan dapat ditarik kesimpulan:

a) Mutu pelayanan perpajakan yang dilakukan oleh pihak Direktorat Jenderal Pajak (DJP) yang dinilai oleh Wajib Pajak Orang Pribadi (WPOP) yang bekerja di Yayasan Bunda Mulia di dalam menjalankan kewajiban perpajakannya berpengaruh positif secara signifikan terhadap kepatuhan Wajib Pajak. Kepatuhan Wajib Pajak yang dijalankan oleh Wajib Pajak Orang Pribadi dipengaruhi oleh mutu pelayanan perpajakan yang dilakukan oleh Direktorat Jenderal Pajak sebesar 17,70\%, sisanya $82,30 \%$ dipengaruhi oleh faktor-faktor lain yang tidak diamati dan diteliti oleh peneliti pada penelitian ini.

b) Kepuasan Wajib Pajak Orang Pribadi yang ada di Indonesia berpengaruh positif secara signifikan terhadap Kepatuhan Wajib Pajak. Kepatuhan Wajib Pajak yang dijalankan oleh Wajib Pajak dipengaruhi oleh kepuasan perpajakan yang dilakukan oleh pihak fiskus (Direktorat Jenderal Pajak - DJP) sebesar 28,4\%, sisanya sebesar $76,1 \%$ dipengaruhi oleh faktor-faktor lain yang tidak diamati dan diteliti oleh peneliti pada penelitian ini.

Berdasarkan pembahasan dan kesimpulan yang didapat maka peneliti menyarankan beberapa hal yang diharapkan dapat membantu Pihak Pemerintah (Direktorat Jenderal Pajak-DJP) dalam memberikan pelayanan dan pengawasan dalam hal kewajiban perpajakan wajib pajak. Saran yang dapat diberikan oleh peneliti sebagai berikut:

1. Karena masih banyak wajib pajak yang belum terbiasa dengan teknologi informasi untuk menjalankan sistem e-filing maka seharusnya KPP memberi pelatihan terlebih dahulu kepada wajib pajak, khususnya pelaporan SPT tahunan dengan sistem e-filing.

2. Mutu pelayanan perpajakan yang diberikan oleh pihak fiskus (Direktorat Jenderal Pajak) harus terus ditingkatkan dengan melakukan training center bagi petugas pajak khususnya Account Reprensentaitve (AR) agar dapat meningkatkan mutu pelayanan perpajakan.

3. Kepuasan Wajib Pajak dalam melakukan kewajiban perpajakannya masih harus ditingkatkan oleh Direktorat Jenderal Pajak (DJP), karena pada penelitian ini wajib pajak yang menjadi responden hanya sebesar 28,4\% yang merasakan puas atas pelayanan perpajakan yang diberikan oleh fiskus (Direktorat Jenderal Pajak).

4. Diharapkan Direktorat Jenderal Pajak meningkatkan kinerja sistem online yang ada, sehingga dapat mengurangi terjadinya error pada sistem $e$-filing ketika diakses oleh wajib pajak orang pribadi (WPOP).

5. Mengadakan sosialisasi bahwa dengan e-filing wajib pajak akan sangat terbantu karena tidak perlu mengantri ke Kantor Pelayanan Pajak dan bisa dilakukan dimana saja dan kapan saja. Agar wajib pajak menggunakan e-filing dengan sukarela bukan karena diwajibkan oleh KPP, sehingga dapat meningkatkan efektivitas pemrosesan data perpajakan. 


\section{National Conference of Creative Industry: \\ Sustainable Tourism Industry for Economic Development}

Universitas Bunda Mulia, Jakarta, 5-6 September 2018

e-ISSN No: 2622 - 7436

\section{DAFTAR PUSTAKA}

Afridi, S.A. and Khattak, A. (2013). Impact of Trust on Customer Advocacy: A Study Regarding Health Sector of Peshawar. Abasyn Journal of Social Sciencies, 8 (2), 355-362.

Amin, M. (2016). Model Dinamika Penerapan E-Government dengan pendekatan Darcy (Kasus Kementrian Koordinator Perekonomian, Kementerian Keuangan, dan Kementerian Riset, Teknologi, dan Pendidikan Tinggi). diaksespada tanggal 01 Juli 2017, dari http://www.ui.ac.id/berita/dinamika-penerapan-e-government-di indonesia.html.

Anderson, E. and Srinivasan, S. S. (2003). E-Satification and E-Layalty: A Contingency Framework. Psychology and Marketing Journal, 20 (2), 123-138.

Ayo, C.K., Oni, A. A., Adewoye, O.J., and Eweoya, I. O. (2016). E-banking users' behavior: e-service quality, attitude, and customer satisfication. International Journal of Banking Marketing, 34 (3), 347-367.

Carter, L. and Belanger, F. (2005). The Utilizations of e-government services: citizen trust, innovation and acceptance factors. Information Systems Journal, 15 (1), 2 25 .

Chen, M. and Qi, X. (2015). Members' satification and continuances intention: a sociotechnical perspective. Industrial Management and Data Systems, 115 (6), 1132-1150.

Fang, Y. H., Chiu, C. M., and Wang, E. T. G. (2011). Understanding customers' satification and repurchase intentions: An integration of IS success model, trust, and justice. Internet Research, 21 (4), 479-503.

Fang, Z. (2002). E-Government in digital era: concept, practice, and development. International Journal of the Computer, the Internet and Management, 10 (2), 122

Desmayanti, E. dan Zulaikha. 2012. Faktor-faktor yang Mempengaruhi Penggunaan Fasilitas e-Filling oleh Wajib Pajak sebagai Sarana Penyampaian SPT Masa secara onlinedan realtime.Diponegoro Journal of Accounting, 1 (1), 1-12.

Direktorat Jenderal Pajak Kementrian Keuangan.(2017).DJP dan PKP Siap Melaksanakan E-Faktur. Diakses pada tanggal 10 Februari 2017,dari "http://www.pajak.go.id/content/article/djp-dan-pkp-siap-melaksanakan-e-faktur

Direktorat Jenderal Pajak Kementrian Keuangan. (2017). E-SPT.Diakses pada tanggal 10 Februari 2017,dari http://www.pajak.go.id/e-spt.

Direktorat Jenderal Pajak Kementrian Keuangan. (2017).Mudahnya Pelaporan Pajak melalui e-Filing. Diakses pada tanggal 10 Februari 2017, dari http://www.pajak.go.id/content/mudahnya-pelaporan-pajak-melalui-e-filing.

Direktorat Jenderal Pajak Kementrian Keuangan. Pendaftaran NPWP Online (eRegistration).Diakses pada tanggal 10 Februari 2017, dari http://www.pajak.go.id/content/pendaftaran-npwp-online-e-registration 


\section{National Conference of Creative Industry: \\ Sustainable Tourism Industry for Economic Development}

Universitas Bunda Mulia, Jakarta, 5-6 September 2018 e-ISSN No: 2622 - 7436

Direktorat Jenderal Pajak Kementrian Keuangan. (2017).Sistem Pembayaran Pajak Secara Elektronik (Billing System). Diakses pada tanggal 10 Februati 2017, dari http://www.pajak.go.id/content/billing-system.

Direktorat Jenderal Pajak Kementrian Keuangan. (2017). Undang-Undang Republik Indonesia Nomor 6 tahun 2009 tentang Ketentuan Umum dan Tata Cara Perpajakan.

Fasmi, L. dan Misra, F. (2012) Pengaruh Modernisasi Sistem Administrasi Perpajakan Terhadap Tingkat Kepatuhan Pengusaha Kena Pajak di Kantor Pelayanan Pajak (KPP) Pratama Padang.Jurnal Simposium Nasional Akuntansi 15.

Hair, J. F., Black, W. C., and Babin, B.J. (2013). Multivariate Data Analysis: A global perspective. ( $7^{\text {th }}$ edition). United Kingdom: Pearson Education.

Harrisson, W. (2001). The measurement of word-of-mouth communication and an investigation of service quality and customer commitment as potential antecedents. Journal of Service Research, Vol.4 (1), pp.60-75.

Hartono, J. (2013). Metodologi Penelitian Bisnis: Salah Kaprah dan PengalamanPengalaman. Edisi 6. Yogyakarta: Fakultas Ekonomika dan Bisnis UGM.

Laihad, Risal C. Y. (2013). "Pengaruh Perilaku Wajib Pajak terhadap Penggunaan eFilling Wajib Pajak di Kota Manado.” Jurnal EMBA, volume 1, no.3. pp. 44-51.

Lie, I. dan Sadjiarto, A.(2013). Faktor-Faktor Yang Mempengaruhi Minat Perilaku Wajib Pajak Untuk Menggunakan e-Filing. Tax \& Accounting Review, 3 (2), 1-15.

Lingga, I. S. (2012). "Pengaruh Penerapan $e-S P T$ Terhadap Efisiensi Pemrosesan Data Perpajakan." Jurnal Akuntansi, 4 (2), 101-114.

Papadomichelaki, X. and Mentzas, G. (2012). E-GovQual: A multiple-item scale for assessing E-Government Service Quality. Government Information Quarterly, Vol. 29 (1), 98-109.

Priyatno, Duwi. (2016). SPSS Handbook: Analisis Data, Olah Data, \& Penyelesaian Kasus-Kasus Statistik. Jakarta: PT Buku Seru.

Rahayu, S. dan Lingga, I.S. (2009). Pengaruh Modernisasi Sistem Administrasi Perpajakan terhadap Kepatuhan Wajib Pajak Badan pada KPP Pratama Bandung. Jurnal Akuntansi. 1 (2), 119-138.

Richardson, G. (2006), Determinants of tax evasion: A cross-country investigation, Journal of International Accounting, Auditing and Taxation, 1 (1), 150-169.

Rusli, Y. M. (2012). The Influence of Tax Payer's Awareness, Tax Service, and Tax Morale against Tax Payment and Tax Evasion, study in Bandung city. Thesis, Universitas Kristen Maranahta, Bandung.

Sekaran, U. and Bougie, R. (2009). Research Methods for Business: A Skill Building Approach $\left(7^{\text {th }}\right.$ Ed.). United Kingdom: Willy Son.

Shang, S (2014). Assessment of E-Government Service Quality Under User Satisfaction Orientation: The Estabilishment of E-Govqual Model. Asean Journal of Business Management, 6 (2), 111-117.

Sharma, S. k. (2015). Adoption of E-Government Services: The Role of Service Quality Dimenssions and Demographic Variabels. Tranforming Government: People, Process and Policy, 9 (2), 207-222.

Slemrod, Joel B and Marsha Blumenthal. (2006). The Income Tax Compliance Cost of Big Business. Public Finance Quarterly, 24 (14)

Suharyadi \& S.H., Purwanto. (2013). Statistika: Untuk Ekonomi dan Keuangan Modern. Jakarta: Salemba Empat. 


\section{National Conference of Creative Industry: \\ Sustainable Tourism Industry for Economic Development}

Universitas Bunda Mulia, Jakarta, 5-6 September 2018 e-ISSN No: 2622 - 7436

Sujarweni, V.W. (2014). Metodologi Penelitian: Lengkap, Praktis dan Mudah Dipahami. Yogyakarta: Pustaka Baru Press.

Suryabrata, S. (2014). Metodologi Penelitian. Jakarta: Rajawali Pers.

Susanta, Alhabsji, T., Idrus, M. S., and Nimran, U. (2013). The Effect of Relationship Quality on Customer Advocacy: The Mediating Role of Loyalty. IOSR Journal of Business and Management, 10 (4), 41-52

Torgler, B. and Schenaider, F. (2007). The Impact of Tax Morale and Institutional Quality on the Shadow Economy Journal, IZA DP No 2541

Torgler, B., Schaffner, M. and Schategger, C.A. (2003), Is Forgiveness Divine? A CrossCulture Comparison of Tax Amnesties, Swiss Journal of Economics and Statistics, 139 (3), 375-396.

Waluyo. Perpajakan Indonesia. Edisi ketiga. Buku satu. Jakarta : Salemba Empat, 2015.

Wibisona, L.T dan Toly, A. A. 2014. Analisis Faktor-Faktor yang Mempengaruhi Minat Wajib Pajak dalam menggunakan e-filing di Surabaya. Tax and Accounting Review Journal, 4 (1)

Yeh, Y. P. (2013). The Impact of Customer Advocacy on Customer Perceived Value. Journal of Business and Ritail Management Research, 8 (1), 91-102. 